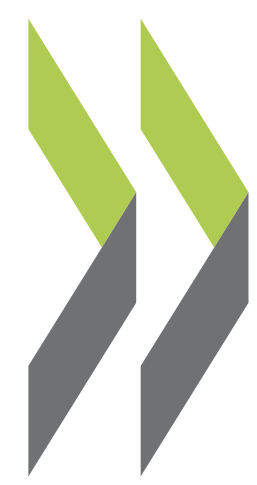

OECD Economics Department Working Papers No. 548

The Political Economy

of Delaying Fiscal

Boris Cournède

Consolidation 
Organisation de Coopération et de Développement Economiques

Organisation for Economic Co-operation and Development

09-Mar-2007

ECONOMICS DEPARTMENT

English - Or. English

THE POLITICAL ECONOMY OF DELAYING FISCAL CONSOLIDATION

Economics Department Working Paper No. 548

by Boris Cournède

All Economics Department Working Papers are available through OECD internet website at www.oecd.org/eco/Working_Papers 


\section{ABSTRACT/RESUMÉ \\ The political economy of delaying fiscal consolidation}

Over the next decades, many OECD countries are anticipating large increases in public spending as a result of population ageing and other long-term structural trends. The need to put public finances on a sustainable footing is widely recognised, but progress has been uneven and slow. Some policy makers may feel that action can be deferred for a few years at little cost because of the long-term nature of the problem. This paper questions this perception by proposing a model of the political costs of consolidating public finances. The main finding is that even a short delay increases political cost of consolidation quite markedly when ultimately policy makers are facing a deadline by which sustainability must be restored. The conclusion is very robust to changes in assumptions and specification. A variant of the model shows that with an infinite horizon the incentive to consolidate is weaker, which highlights the importance of setting a deadline.

This paper relates to the 2007 Economic Survey of the Euro area (www.oecd.org/eco/surveys/euroarea).

Key words: public finances; fiscal consolidation; political economy; structural adjustment; population ageing. JEL codes: E62; D72.

\section{L'économie politique du retard à consolider les finances publiques}

De nombreux pays de l'OCDE s'attendent à enregistrer de forte hausses de leurs dépenses publiques en raison du vieillissement démographique et d'autres tendances structurelles lourdes. Presque tout le monde s'accorde à reconnaître qu'il est nécessaire de rétablir la viabilité des finances publiques, mais peu de progrès ont été enregistrés. Il se pourrait que certains décideurs considèrent que la mise en œuvre de mesures puisse être reportée pour quelques années sans qu'il n'en coûte beaucoup. Cette étude met en cause ce jugement en proposant un modèle du coût politique de la consolidation budgétaire. Le résultat principal est que même un court délai augmente le coût politique de la consolidation de manière importante lorsqu'au final les décideurs sont confrontés à une date limite à laquelle la viabilité budgétaire doit être rétablie. Ce résultat est très robuste à des changements d'hypothèses ou de spécification. Une variante du modèle montre qu'avec un horizon temporel infini l'incitation à consolider est plus faible, ce qui souligne combien il importe de fixer une date limite.

Ce document se rapporte à l'Étude économique de zone euro 2007 (www.oecd.org/eco/etudes/zoneeuro).

Mots clés : Finances publiques ; consolidation budgétaire ; économie politique ; ajustement structurel ; vieillissement démographique.

Classification JEL : E62 ; D72.

To see previous ECO Working Papers, go to www.oecd.org/eco/working papers.

\section{Copyright OECD, 2007}

Application for permission to reproduce or translate all, or part of, this material should be made to: Head of Publications Service, OECD, 2 rue André Pascal, 75775 Paris Cedex 16, France. 
TABLE OF CONTENTS

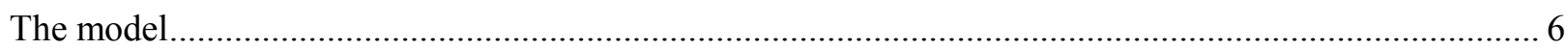

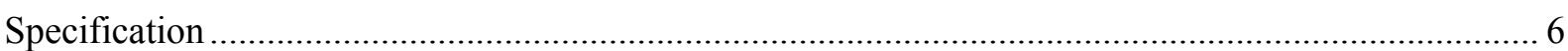

Solution

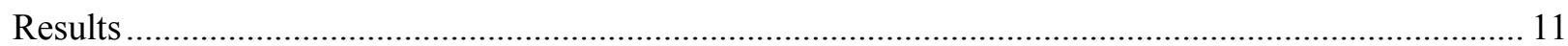

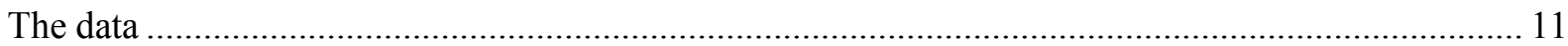

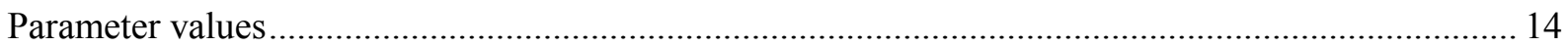

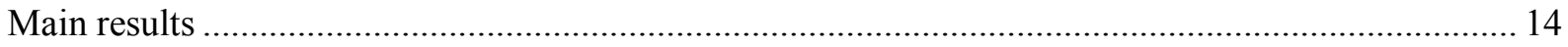

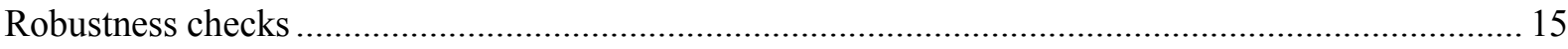

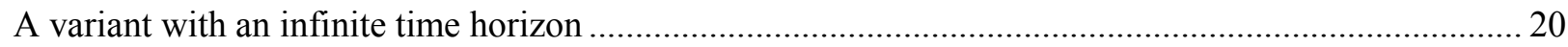

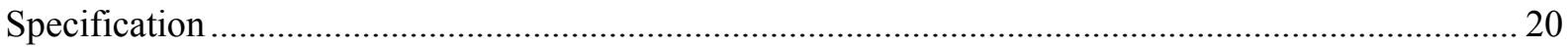

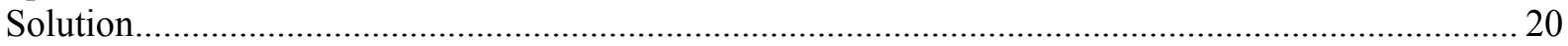

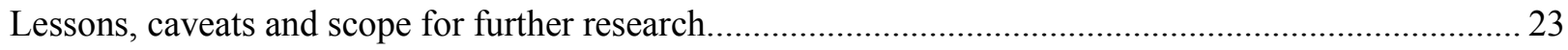

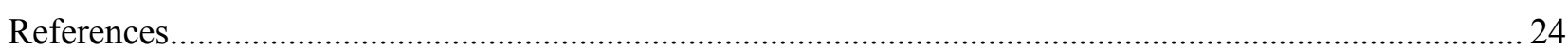


ECO/WKP(2007)8 
ECO/WKP(2007)8

\title{
THE POLITICAL ECONOMY OF DELAYING FISCAL CONSOLIDATION
}

\author{
by \\ Boris Cournède ${ }^{1}$
}

1. Most OECD countries will have to consolidate their public finances in order to put them on a sustainable track in the face of long-term spending pressures stemming from ageing and other structural trends (OECD, 2006; EC, 2006). The need to consolidate is widely recognised but progress has been uneven and slow. Many policy makers consider consolidation as very costly in political terms because the impact of tax increases and expenditure cutbacks are felt immediately while the benefits of restored sustainability may be perceived only later. They may also consider that action can be deferred at little cost because of the long-term nature of the problem. This paper questions this perception by proposing a stylized model of the political cost of fiscal consolidation and looking at how it is affected by the timing of action. $^{2}$

2. This paper focuses on political economy considerations because they often constitute a major hurdle to fiscal consolidation. They are not, however, the only obstacle to redressing public finances (see Lavigne, 2006 for a recent survey of other obstacles). For instance, initiating a consolidation effort in the presence of cyclical slack poses the risk of triggering a recession through negative multiplier effects even though the risk may be lower than commonly thought because a credible shift towards a sustainable fiscal position can generate favourable non-linear effects (Giavazzi and Pagano, 1996; Cotis and Koen, 2005).

3. Does it pay to wait before embarking on a fiscal consolidation programme? Some studies have highlighted situations where voters tend to reward governments who redress their public finances (see for instance Alesina et al., 1998 and Brender and Drazen, 2006). In such cases, waiting obviously does not pay. This paper examines the question in other, presumably more usual, situations where there is some cost attached to large shifts in the fiscal stance as evidenced by von Hagen et al. (2001), Hughes-Hallet et al. (1998) and Bradley et al. (1993). Indeed, consistent with the view that policy makers anticipate being penalised at the polls for fiscal tightening and rewarded for loosening, a large body of empirical literature has found a clear tendency towards fiscal easing in the run-up to anticipated elections (see for instance Buti and van den Noord, 2004).

4. The main finding here is that even a relatively short delay before starting to act increases the political cost of consolidation quite markedly. As an illustration, consider that consolidation is defined as bringing debt to zero by 2025 in order to make room for ageing-related cost pressures before they start to

1. The author is a member of the OECD Economics Department and can be contacted at boris.cournede@oecd.org. This work was carried out in preparation for the OECD Economic Survey of the Euro Area 2007 (www.oecd.org/eco/euroarea). The views expressed in this paper are those of the author and do not necessarily represent those of the OECD or its member countries. The author is indebted to Peter Hoeller, Paul van den Noord, David Rae and Jean-Luc Schneider for suggestions and helpful discussions on earlier drafts. The author also wishes to thank Priscilla Cournède, Romain Duval, Christian Gianella and Dave Turner for useful comments as well as Celia Rutkoski for technical preparation.

2. A different question is to evaluate the economic costs of delaying fiscal consolidation (see for instance Koutsogeorgopoulou and Turner, 2007). 
bite in earnest. Based on dynamic optimisation techniques, the model enables calculating optimal fiscal consolidation paths to get there - optimal from a political economy point of view in the sense that they minimise the discounted political cost incurred by policy makers while meeting the objective. For the euro area and using a subjective discount rate of $6 \%$, waiting for two years before starting to act raises the lowest possible cost of consolidation to policy makers by $13 \%$. A variant of the model highlights the importance of setting a deadline for consolidation: policy makers faced with an infinite time horizon will find it politically optimal to postpone adjustment indefinitely, but this model does not include a feed back of a massive debt build up on interest rates and growth.

\section{The model}

\section{Specification}

5. The model rests on a stylised representation of the costs of consolidation to decision makers, taking two sources of cost into account: the speed at which adjustments are made and their size. At time $t=0$, the policy maker decides on a consolidation strategy, that is to say on a path of adjustment $f_{t}$ from time $t=0$, or $t=l a g$ if he or she procrastinates, until the horizon $T$. The primary deficit $\bar{d}_{t}$ at time $t$ can be written as the sum of the adjustment effort $f_{t}$ and the spontaneous deficit arising from the initial fiscal stance $d_{0}$ and the long-term cost pressures $x_{t}$ (Equation 1). The adjustment $f_{t}$ can be made on long-term cost pressures $x_{t}$ or on the primary deficit excluding long-term cost pressures $d_{t}=f_{t}+d_{0}$ or on a combination of both.

$$
\bar{d}_{t}=f_{t}+d_{0}+x_{t}
$$

6. Abrupt swings in fiscal policy settings typically entail large costs to policy makers. The main reason is that sudden changes in the fiscal stance can destabilise the economy. In addition, large fiscal changes usually have significant distributional implications which can impose considerable costs on policy makers (Alesina and Drazen, 1991). Akin to Dornbusch (1991), a quadratic loss function of the adjustment speed $\dot{f}_{t}$ is used to incorporate this non-linearity in a simple way. This source of cost receives weight $\alpha$ and is discounted to the time $t=0$ when the policy maker is pondering the options (Equation 2). The letter $\delta$ denotes the policy maker's subjective rate of time preference.

$$
l_{t}^{\text {speed }}=\alpha\left(\dot{f}_{t}\right)^{2} e^{-\delta t}
$$

7. In addition to its speed, the size of the adjustment effort also affects the political cost of consolidation. Current levels of taxation, public spending and entitlements reflect a form of political equilibrium with the implication that adjusting them involves political costs. As in Dornbusch (1991), this source of cost is modelled with a quadratic loss function of $f_{t}$ because these effects are also non-linear. Equation 3 sets out the specification of the loss function, which is based on the adjustment effort $f_{t}$ corrected by the initial level of the primary deficit $d_{0}$. The corrected adjustment effort $f_{t}+d_{0}$ is denoted by $d_{t}$ because it is equal to the primary budget deficit excluding long-term pressures. In particular the equality $d_{t}=\bar{d}_{t}=d_{0}$ holds when $t=0$. The corrected adjustment effort $d_{t}$ is used rather than $f_{t}$ to reflect that initially unbalanced budget positions entail a cost to policy makers. Deficits convey a perception of bad management while surpluses typically imply that the authorities come under pressure to spend more and tax less. Running surpluses to repay debt is unpopular as the electorate usually does not appreciate being taxed to cover the cost of past spending programmes. Running primary surpluses to pre-fund future 
expenditure commitments can be equally unpopular because the people who may benefit are not necessarily the ones who pay. The letter $a$ stands for the weight this source of cost takes in the policy maker's objective function.

$$
\text { (3) } l_{t}^{\text {size }}=a\left(f_{t}+d_{0}\right)^{2} e^{-\delta t}=a\left(d_{t}\right)^{2} e^{-\delta t}
$$

8. While there is widespread agreement that large and abrupt changes in the fiscal stance usually entail substantial political costs, it can be argued that once the necessary adjustment has been completed, maintaining sound policy settings involves lower political costs - or even none at all. This leads to choosing parameter values $a$ and $\alpha$ that give a stronger weight to the speed-based component $l^{\text {speed }}$ than to the size-based component $l^{\text {size }}$ in the overall loss function policy makers are minimising (see section on calibration below). More importantly, care has been taken to specify and solve the model in such a way that all the analytical formulae remain valid and therefore allow the calculation of results when the second source of political cost is eliminated by setting $a=0$. Corresponding results reported in the robustness check section show that the main findings (namely that in most countries delaying fiscal consolidation entails large political costs) hold when the parameter $a$ is set equal to 0 .

9. Overall, the instantaneous loss function $l_{t}$ of fiscal policy makers is specified as (4). After noting that $\dot{f}_{t}=\dot{f}_{t}+\dot{d}_{0}=\dot{d}_{t}$, equation 4 can be rewritten as (5). The interest of (5) is that the instantaneous loss function is expressed only in terms of the deficit excluding long-term cost pressures $d_{t}$.

$$
\begin{gathered}
\text { (4) } l_{t}=l_{t}^{\text {speed }}+l_{t}^{\text {size }}=\alpha\left(\dot{f}_{t}\right)^{2} e^{-\delta t}+a d_{t}^{2} e^{-\delta t} \\
\text { (5) } l_{t}=\left(\alpha \dot{d}_{t}{ }^{2}+a d_{t}{ }^{2}\right) e^{-\delta t}
\end{gathered}
$$

10. With $r$ and $\gamma$ standing for the long-term real interest rate and the rate of real GDP growth, the debt to GDP ratio $b_{t}$ follows the law of motion set out by equation (6):

$$
\dot{b}_{t}=(r-\gamma) b_{t}+d_{t}+x_{t}
$$

11. The policy maker acts so as to minimise the present value of discounted future losses $L$ as expressed in (7) under the constraint of fiscal sustainability. The sustainability constraint takes the simple form of maintaining the debt ratio below a target level $b^{*}$ at horizon $T$ (equation 8). The model throws light on the choices facing policy makers in countries where fiscal consolidation is required to restore sustainability, in which case the constraint is binding (9). Whether or not the constraint (8) is binding has been checked systematically in all numerical results reported below. In the rare cases where the sustainability constraint was found to be non-binding, the reported results were calculated using a solution for the unconstrained problem. ${ }^{3}$

$$
L=\int_{0}^{T}\left(\alpha \dot{d}_{t}^{2}+a d_{t}^{2}\right) e^{-\delta t} d t
$$

$$
\begin{aligned}
& b_{T} \leq b^{*} \\
& b_{T}=b^{*}
\end{aligned}
$$

3. The solution of the unconstrained problem is available from the author. It is not presented here because it offers little interest and can be easily obtained by adapting the derivation of the solution for the constrained problem (which is considerably simpler in the unconstrained case). 


\section{Solution}

12. The policy maker chooses the path of deficits $d_{t}$ that minimises $L$ under constraint (9). Technically, it is convenient to consider that the policy maker chooses $d_{t}$ and $b_{t}$ simultaneously so as to minimise $L$ under the constraint (6) and with the boundary condition (9). This representation is fully equivalent to the initial problem, but it offers the advantage of transforming the integral constraint (9) into a boundary condition on $b_{t}$, which is technically more tractable. The price to pay is that (6) becomes a constraint, but this can be handled through the introduction of a time-varying Lagrange multiplier $\lambda_{t}$.

13. The problem is equivalent to the unconstrained maximisation of the generalised Lagrangian $\widetilde{L}$ defined by equation 10 . For the sake of convenience, the instantaneous Lagrangian loss function $\widetilde{l}_{t}$ is introduced and equation (10) is rewritten as (11). Since the system involves three unknown time-varying variables $b, d$ and $\lambda$, three boundary conditions are needed to determine a unique solution in the absence of singularity. ${ }^{4}$ The sustainability condition (9) provides one. The initial level $d^{\circ}$ of the primary deficit before the policy maker starts to consolidate provides a second one (Equation 12). A natural transversality condition for the problem is that debt should be stable at the end of the consolidation period $\left(\dot{b}_{T}=0\right)$, which provides the third boundary condition (13).

$$
\begin{gathered}
\widetilde{L}=\int_{0}^{T}\left[\left(\alpha \dot{d}_{t}^{2}+a d_{t}^{2}\right) e^{-\delta t}-\lambda_{t}\left(\dot{b}_{t}-(r-\gamma) b_{t}-d_{t}-x_{t}\right)\right] d t \\
\widetilde{L}=\int_{0}^{T} \tilde{l}_{t} d t \text { with } \tilde{l}_{t}=\left(\alpha \dot{d}_{t}^{2}+a d_{t}^{2}\right) e^{-\delta t}-\lambda_{t}\left(\dot{b}_{t}-(r-\gamma) b_{t}-d_{t}-x_{t}\right) \\
\text { (12) } \quad d_{0}=d^{0} \\
\text { (13) } d_{T}=-x_{T}-(r-\gamma) b^{*}
\end{gathered}
$$

14. To summarise, the problem is to find $b, d$ and $\lambda$ that minimise $\widetilde{L}$ with the boundary conditions (9), (12) and (13). The theory of the calculus of variations indicates that at the optimum the Euler-Lagrange derivatives of the instantaneous Lagrangian loss function $\tilde{l}_{t}$ with respect to $b, d$ and $\lambda$ are equal to zero (see for instance Bourguignon, 1989). The Euler-Lagrange derivatives with respect to $b$ and $d$ provide the first-order differential equation (14) and the second-order differential equation (15). ${ }^{5}$ The Euler-Lagrange derivative with respect to $\lambda$ yields an equation identical to the law of motion (6).

$$
\dot{\lambda}_{t}=(r-\gamma) \lambda_{t}
$$

$$
\alpha \ddot{d}-\alpha \delta \dot{d}-a d-\frac{1}{2} \lambda_{t} e^{\delta t}=0
$$

4. The absence of singularity is assumed. This assumption is verified in all the practical cases considered: the solution matrix has full rank in all cases.

5. The Euler-Lagrange derivative of a function $f_{t}(y, \dot{y})$ with respect to the variable $y$ is by definition equal to $\nabla_{y} f-\frac{d}{d t} \nabla_{\dot{y}} f$ where $\nabla$ denotes the gradient operator. Detailed calculation steps are available from the author. 
15. Equation (15) is central as it governs the main variable of interest - the primary budget deficit excluding long-term cost pressures $d_{t}$ that minimises the political cost of consolidation. Before solving (10), more information is needed about the behaviour of the Lagrange multiplier $\lambda_{t}$. Determined by a homogeneous first-order differential equation, $\lambda_{t}$ varies according to the exponential formula (16). This has interesting consequences for the main equation (15): rewritten as (17) it becomes a linear second-order differential equation with constant coefficients. As a result, and since the non-homogenous term can be integrated analytically, an analytical solution can be found for the optimal path of the deficit $d_{t}$ of the budget excluding long-term cost pressures.

$$
\lambda_{t}=\lambda_{0} e^{(r-\gamma) t}
$$

$$
\alpha \ddot{d}-\alpha \delta \dot{d}-a d-\frac{1}{2} \lambda_{0} e^{(r-\gamma+\delta) t}=0
$$

$$
\alpha \ddot{d}-\alpha \delta \dot{d}-a d=0
$$

16. Equation (17) can be solved in two steps. The first one is to identify the two characteristic solutions of the associated homogeneous equation (18). The second step is to find one particular solution for the full, non-homogenous equation (17). All solutions of (17) are then known to be equal to the sum of the particular solution and a linear combination of the two characteristic solutions of (18).

- The characteristic solutions of (18) are found by finding the roots of the second-order polynomial equation $\alpha \rho^{2}-\alpha \delta \rho-a d=0$. Given that the polynomial discriminant $\alpha^{2} \delta^{2}+4 \alpha a$ is strictly positive, the equation has two solutions $\rho_{l}$ and $\rho_{2}$ given by (14). The differential equation (18) therefore leads to the two characteristic solutions $e^{\rho_{1} t}$ and $e^{\rho_{2} t}$.

$$
\rho_{1}=\frac{1}{2}\left(\delta+\sqrt{\delta^{2}+4 \frac{a}{\alpha}}\right) \text { and } \quad \rho_{2}=\frac{1}{2}\left(\delta-\sqrt{\delta^{2}+4 \frac{a}{\alpha}}\right)
$$

- The function $k e^{(\delta-r+\gamma) t}$, where $k$ is a constant scalar, is a particular solution of (17). ${ }^{6}$

All solutions of (17) therefore take the form (20) where $c_{1}, c_{2}$ and $k$ are scalars.

$$
d_{t}=c_{1} e^{\rho_{1} t}+c_{2} e^{\rho_{2} t}+k e^{(\delta-r+\gamma) t}
$$

17. As expected, the politically optimal deficit path will be more back-loaded if policy makers have a higher discount rate $\delta$. The formula for the optimal deficit rewritten as (21) indeed exhibits two terms in $e^{\frac{1}{2} \delta t}$ and one term in $e^{\delta t}$, which all tend to shift the adjustment further in the future as $\delta$ rises.

$$
d_{t}=c_{1} e^{\frac{1}{2}\left(\delta+\sqrt{\delta^{2}+4 \frac{a}{\alpha}}\right) t}+c_{2} e^{\frac{1}{2}\left(\delta-\sqrt{\delta^{2}+4 \frac{a}{\alpha}}\right) t}+k e^{(\delta-r+\gamma) t}
$$

6. The scalar $k$ is related to $\lambda_{0}$ by the formula : $k=\frac{\lambda_{0}}{2\left(\alpha v^{2}-\alpha \delta v-\alpha\right)}$ where $v$ stands for $\delta-r+\gamma$. Since $\lambda_{0}$ is indeterminate given the form taken by the boundary conditions, this formulation shows that any scalar $k$ is a priori acceptable in the solution of (17). 
18. The expression (20) can be used directly in the boundary conditions that define the initial and end values of the deficit (Equations 12 and 13). This provides two linear equations for three unknown scalar variables $c_{1}, c_{2}$ and $k$. The final step to derive the optimal deficit path in full is to calculate $b_{t}$ using $c_{1}, c_{2}$ and $k$. This can be done by using the formula (20) for $d_{t}$ in the general solution of the law of motion (6).

19. The general solution of the law of motion (6) governing the debt ratio can be written as (22). Formula (22) has a direct economic interpretation. The first term determining the debt ratio after time $t$ is equal to the initial debt ratio magnified by the exponential factor $e^{(r-\gamma) t}$ which reflects the amplification effects of the debt dynamics if the real interest rate is higher than real GDP growth. If on the contrary the real interest rate is lower than the real GDP growth rate, then the debt dynamics is contractionary. The second term determining the debt ratio is in essence identical to the first: over the infinitesimal period $d u$, the deficit $\bar{d}_{u}=d_{0}+x_{u}+f_{u}=d_{u}+x_{u}$ increases the debt ratio by $\left(d_{u}+x_{u}\right) d u{ }^{7}$ After time $u$, the quantity $\left(d_{u}+x_{u}\right) d u$ is then subject to the same debt amplification mechanism over the remaining time $(t-u)$, hence the factor $e^{(r-\gamma)(t-u)}$.

$$
b_{t}=b_{0} e^{(r-\gamma) t}+\int_{0}^{t}\left(d_{u}+x_{u}\right) e^{(r-\gamma)(t-u)} d u
$$

20. Rearranging the terms in (22) as in (23) highlights another property of the debt path. The consolidation trajectory $d_{t}$ in the budget excluding long-term pressures has to respond to the stock of market debt at time $t=0$ but also to the implicit liability $\hat{b}_{0}^{T}$ associated with the impact of long-term cost pressures over the consolidation horizon.

$$
b_{t}=(b_{0}+\underbrace{\int_{0}^{t} x_{u} e^{-(r-\gamma) u} d u}_{\hat{b}_{0}^{t}}) e^{(r-\gamma) t}+\int_{0}^{t} d_{u} e^{(r-\gamma)(t-u)} d u=\left(b_{0}+\hat{b}_{0}^{t}\right) e^{(r-\gamma) t}+\int_{0}^{t} d_{u} e^{(r-\gamma)(t-u)} d u
$$

21. An explicit expression for $b_{t}$ can be derived by inserting the formula (20) for $d_{t}$ in (23) and integrating the three exponentials that make up $d_{t}$. The result is set out in formula (24). Evaluating $d_{t}$ at $t=0, b_{t}$ at $t=T$ and $d_{t}$ at $t=T$ yields three linear equations for the three unknown scalar variables $c_{1}, c_{2}$ and $k$. This system is summarised in matrix form in (25).

$$
b_{t}=e^{(r-\gamma) t}\left[b_{0}+\hat{b}_{0}^{t}+\frac{e^{\left(\rho_{1}-r+\gamma\right) t}-1}{\rho_{1}-r+\gamma} c_{1}+\frac{e^{\left(\rho_{2}-r+\gamma\right) t}-1}{\rho_{2}-r+\gamma} c_{2}+\frac{e^{(\delta-2(r-\gamma)) t}-1}{\delta-2(r-\gamma)} k\right]
$$

$$
\left(\begin{array}{ccc}
\frac{1}{e^{\rho_{1} T}-e^{(r-\gamma) T}} & \frac{e^{\rho_{2} T}-e^{(r-\gamma) T}}{\rho_{1}-r+\gamma} & \frac{e^{(\delta-(r-\gamma)) T}-e^{(r-\gamma) T}}{\delta-2(r-\gamma)} \\
e^{\rho_{1} T}-r+\gamma & e^{\rho_{2} T} & e^{(\delta-(r-\gamma)) T}
\end{array}\right)\left(\begin{array}{c}
c_{1} \\
c_{2} \\
k
\end{array}\right)=\left(\begin{array}{c}
d^{0} \\
b^{*}-\left(b_{0}+\hat{b}_{0}^{T}\right) e^{(r-\gamma) T} \\
-x_{T}-(r-\gamma) b^{*}
\end{array}\right)
$$

7. Please note that $d u$ denotes an infinitesimal period starting at time $u$ while $d_{u}$ stands for the deficit at time $u$. 
22. Solving (25) for $c_{1,} c_{2}$ and $k$ is the final step as it fully determines the optimal fiscal consolidation path $d_{t}$ through the formula (20). The definition (7) of the cost of adjustment can then be used to evaluate the value of the lowest possible political cost $L_{0}^{T}$ of consolidation between times 0 and $T$. It can then be compared with the least possible cost $L_{0, l a g}^{T}$ that can be achieved if the deficit is kept constant at $d^{\circ}$ between $t=0$ and $t=l a g$ and the adjustment occurs between times lag and $T$. To be comparable with $L_{0}^{T}$, the cost of delayed consolidation $L_{0, \text { lag }}^{T}$ is evaluated at $t=0$ and therefore includes the loss occurred while the deficit is held constant during the inaction period. With $d_{t}^{\text {lag }}$ denoting the deficit path in the delayed consolidation strategy, $L_{0, l a g}^{T}$ is defined by equation (26). The relative cost of delay can then be evaluated by looking at the ratio (27):

$$
\begin{gathered}
L_{0, \text { lag }}^{T}=\int_{0}^{T}\left\lfloor\alpha\left(\dot{d}_{t}^{\text {lag }}\right)^{2}+a\left(d_{t}^{\text {lag }}\right)^{2}\right\rfloor e^{-\delta t} d t=a\left(d^{0}\right)^{2} \operatorname{lag}+\int_{\text {lag }}^{T}\left(\alpha \dot{d}_{t}{ }^{2}+a d_{t}{ }^{2}\right) e^{-\delta t} d t \\
\text { (27) Cost of delay }=\frac{L_{0, \text { lag }}^{T}-L_{0}^{T}}{L_{0}^{T}}
\end{gathered}
$$

\section{Results}

\section{The data}

23. Model results have been calculated for 20 OECD countries (including 12 members of the euro area) and the euro area as a whole. ${ }^{8}$ Projected cost pressures for health and long-term care are those appearing in the OECD (2006) baseline scenario. They have been derived assuming unchanged policies and structural trends. The corresponding hypotheses are detailed in OECD (2006) under the heading "costpressure scenario". Projections of public pension spending are taken from EU EPC (2006) for EU countries, ${ }^{9}$ from Group of Ten (2005) for Canada, Japan, Switzerland and the United States and Dang et al. (2001) for Australia and New Zealand. Overall, all countries are set to come under strong spending pressures over the next decades (Table 1).

8. The reported results cover Australia, Austria, Belgium, Canada, Denmark, Finland, France, Germany, Greece, Ireland, Italy, Japan, Luxembourg, the Netherlands, New Zealand, Portugal, Spain, Sweden, the United Kingdom and the United States. Results can be produced on request for the Czech Republic, Hungary, Korea, Norway, Poland, the Slovak Republic and Switzerland.

9. Projections for public pension spending in Greece, which are not available in EU EPC (2006), have been taken from the 2005 Stability Programme for the country (Greek Ministry of Finance, 2005). 
Table 1. Change in public spending on health care, long-term care and pensions

\begin{tabular}{|c|c|c|c|c|c|c|c|c|}
\hline & \multicolumn{8}{|c|}{ from 2005 levels, in percentage points of GDP } \\
\hline & \multicolumn{2}{|c|}{ Health care } & \multicolumn{2}{|c|}{ Long-term care } & \multicolumn{2}{|c|}{ Pensions } & \multicolumn{2}{|c|}{ Total } \\
\hline & 2025 & 2050 & 2025 & 2050 & 2025 & 2050 & 2025 & 2050 \\
\hline Euro area & 1.5 & 3.7 & 0.9 & 2.2 & 1.1 & 3.0 & 3.5 & 8.9 \\
\hline Austria & 1.5 & 3.8 & 0.6 & 2.0 & 0.1 & -1.0 & 2.2 & 4.8 \\
\hline Belgium & 1.3 & 3.3 & 0.6 & 1.9 & 3.0 & 5.1 & 4.8 & 10.3 \\
\hline Finland & 1.8 & 3.6 & 0.8 & 2.4 & 2.8 & 3.3 & 5.4 & 9.3 \\
\hline France & 1.5 & 3.5 & 0.4 & 1.7 & 1.2 & 2.1 & 3.1 & 7.3 \\
\hline Germany & 1.5 & 3.6 & 0.8 & 1.9 & 0.2 & 2.0 & 2.5 & 7.5 \\
\hline Greece & 1.6 & 3.9 & 1.3 & 2.7 & 4.6 & 10.3 & 7.5 & 16.8 \\
\hline Ireland & 1.6 & 4.0 & 1.5 & 3.8 & 2.5 & 6.5 & 5.6 & 14.4 \\
\hline Italy & 1.6 & 3.8 & 1.3 & 2.9 & 0.2 & 0.4 & 3.1 & 7.0 \\
\hline Luxembourg & 1.4 & 3.7 & 1.3 & 3.1 & 3.7 & 7.4 & 6.3 & 14.3 \\
\hline Netherlands & 1.7 & 3.8 & 0.7 & 2.0 & 2.0 & 3.8 & 4.4 & 9.6 \\
\hline Portugal & 1.6 & 4.2 & 0.6 & 2.0 & 3.9 & 9.3 & 6.1 & 15.5 \\
\hline Spain & 1.6 & 4.1 & 1.1 & 2.4 & 1.8 & 7.0 & 4.5 & 13.5 \\
\hline \multicolumn{9}{|c|}{ Comparator countries } \\
\hline Australia & 1.8 & 4.2 & 0.5 & 2.0 & 1 & 1.7 & 3.3 & 7.9 \\
\hline Canada & 1.9 & 4.1 & 0.6 & 2.1 & 0.8 & 1.7 & 3.3 & 7.9 \\
\hline Denmark & 1.5 & 3.5 & 0.4 & 1.5 & 2.5 & 3.2 & 4.3 & 8.2 \\
\hline Japan & 1.9 & 4.3 & 1.1 & 2.2 & 0.3 & 0.6 & 3.4 & 7.1 \\
\hline New Zealand & 1.8 & 4.2 & 0.6 & 2.0 & 3.2 & 5.9 & 5.7 & 12.0 \\
\hline Sweden & 1.4 & 3.2 & 0.3 & 1.1 & 0.1 & 0.8 & 1.8 & 5.1 \\
\hline United Kingdom & 1.4 & 3.6 & 0.6 & 1.9 & 0.7 & 1.7 & 2.8 & 7.2 \\
\hline United States & 1.5 & 3.4 & 0.4 & 1.7 & 0.9 & 1.8 & 2.9 & 7.0 \\
\hline
\end{tabular}

Sources: OECD (2006), Visco (2005), EU EPC (2006), Dang et al. (2001) and Greek Ministry of Finance (2005).

24. Macroeconomic data are taken from the OECD Economic Outlook 80 database. Debt levels refer to gross liabilities of the general government sector, at market prices (Figure 1). Gross rather than net debt figures have been used because in a number of countries there is no guarantee that government financial assets generate the same return as liabilities. The starting point for the primary deficit path is its cyclicallyadjusted value the year before the adjustment starts. The real GDP growth rate $\gamma$ that enters the calculation is equal to trend growth. A ten-year moving average has been used to produce the long-term real interest rate $r$ used in the calculation. Within the euro area, the area-wide long-term real interest rate is used for all member states for two reasons. First, despite recent divergences in price developments, national long-term inflation expectations eventually have to converge to a single value in a monetary union. Second, spreads between government bond yields are sufficiently small in the euro area that they can be assumed to be nil for the purposes of this model. ${ }^{10}$

10. A refinement of the model could add a feedback from the fiscal position on the interest rate at which the government can borrow. A feedback of this nature would further increase the estimated cost of delaying fiscal consolidation, therefore reinforcing the general conclusion from the analysis. However, including such a feedback would make it impossible to derive an analytical solution, especially since the response of risk premia to fiscal positions would have to be modelled as non-linear (Bernoth et al., 2006). The gain in model accuracy would be small (because this study only considers relatively short delays of two to four years) and would come at the price of having to use purely numerical methods and losing analytical solutions such as (21) and (24), which have the advantage of showing how different factors interact. 
Figure 1. Government debt

Per cent of GDP, 2006

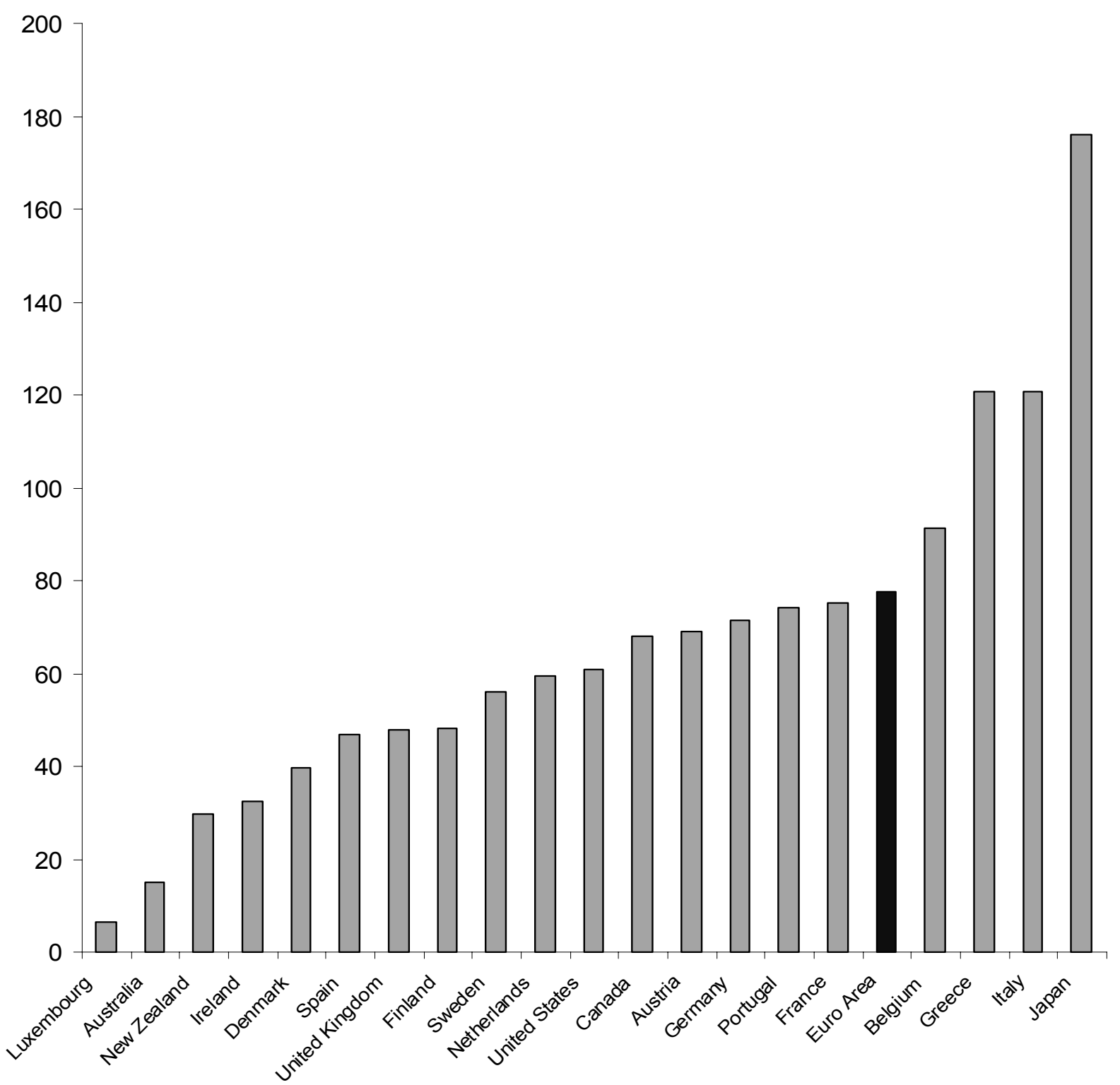

Note: Debt refers to gross financial liabilities, measured at market prices. Source: OECD Economic Outlook 80. 


\section{Parameter values}

25. The following parameter values have been used in the base case scenario, the results of which are reported in Table 2:

- The coefficients of the loss functions are $\alpha=2$ and $a=0.1$. These values have been chosen to give more weight to the speed of adjustment than its magnitude: running a 3\% deficit has the same cost as cutting the deficit by $0.67 \%$ of GDP.

- The subjective rate of time preference $\delta$ is set at $6 \%$, well above the upper end of the usual 2-3\% range (Gallon and Masse, 2004; Gourinchas and Parker, 2002), to reflect the common perception that policy makers tend to have a shorter horizon than investors.

26. The model has been run for scenarios where debt is brought back to zero by 2025 to make room for ageing-related cost pressures. There is a strong case based on political economy and inter-generational equity grounds for going further and building a net asset position so as to pre-fund spending pressures associated with the demographic transition (OECD, 2005). However, given the difficulty of quantifying the desirable net asset position, aiming at zero debt is a reasonable if conservative assumption.

\section{Main results}

27. The political costs of delaying consolidation for two years turn out to be surprisingly large in most cases, at $13 \%$ for the euro area and reaching 24\% for Japan (Table 2). Waiting increases the political cost of consolidating even though policy makers' assumed preference for the present translates into consolidation paths that are fairly back-loaded (Figure 2). In spite of this tendency to push back efforts in the future, the nature of the debt dynamics is such that keeping the primary deficit constant for two years before starting to adjust increases the cost of consolidation quite markedly.

Table 2. The political cost of delaying consolidation for two years is large in many countries

Relative cost of delay when consolidation starts in 2009 rather than 2007

\begin{tabular}{lclclc}
\hline \multicolumn{5}{c}{ Per cent } \\
\hline Euro Area & $13(7 / 57)$ & France & $15(8 / 54)$ & Netherlands & $5(2 / 40)$ \\
Australia & $13(1 / 9)$ & Germany & $15(7 / 48)$ & New Zealand & $2(0 / 22)$ \\
Austria & $8(3 / 35)$ & Greece & $11(15 / 133)$ & Portugal & $16(12 / 78)$ \\
Belgium & $3(2 / 75)$ & Ireland & $7(2 / 23)$ & Spain & $1(0 / 26)$ \\
Canada & $8(3 / 42)$ & Italy & $19(27 / 140)$ & Sweden & $6(1 / 24)$ \\
Denmark & $0(0 / 23)$ & Japan & $24(67 / 276)$ & United Kingdom & $22(6 / 27)$ \\
Finland & $4(1 / 32)$ & Luxembourg & $17(3 / 19)$ & United States & $18(7 / 38)$ \\
\hline
\end{tabular}

Note: the ratios have been calculated using formula (27). They indicate by how much the minimum possible political cost of consolidation increases if action starts in 2009 rather than 2007. For each ratio, the corresponding numerator (the absolute cost of delay) and denominator (the full cost of consolidation if starting now) are shown between brackets.

Source: Author's calculations. 
28. The main values reported in Table 2 (those that are not between brackets) are indicative of the political cost of delaying fiscal consolidation for each country considered individually but they cannot be compared across countries. The reason is that the reported cost of inaction is expressed relative to the full cost of consolidation in the country. As a consequence, a country with a lower absolute cost of delay (e.g. the United Kingdom) than another one (e.g. Italy) can exhibit a higher relative cost of delay ( $22 \%$ against $19 \%$ ) because it has a lower full cost of consolidation (27 against 140) entering the ratio as a denominator. The full cost of consolidation is tightly linked to the debt burden and the size of long-term cost pressures.

Figure 2. Politically optimal consolidation paths

Primary surplus in the budget excluding long-term cost pressures, as a ratio to GDP, per cent

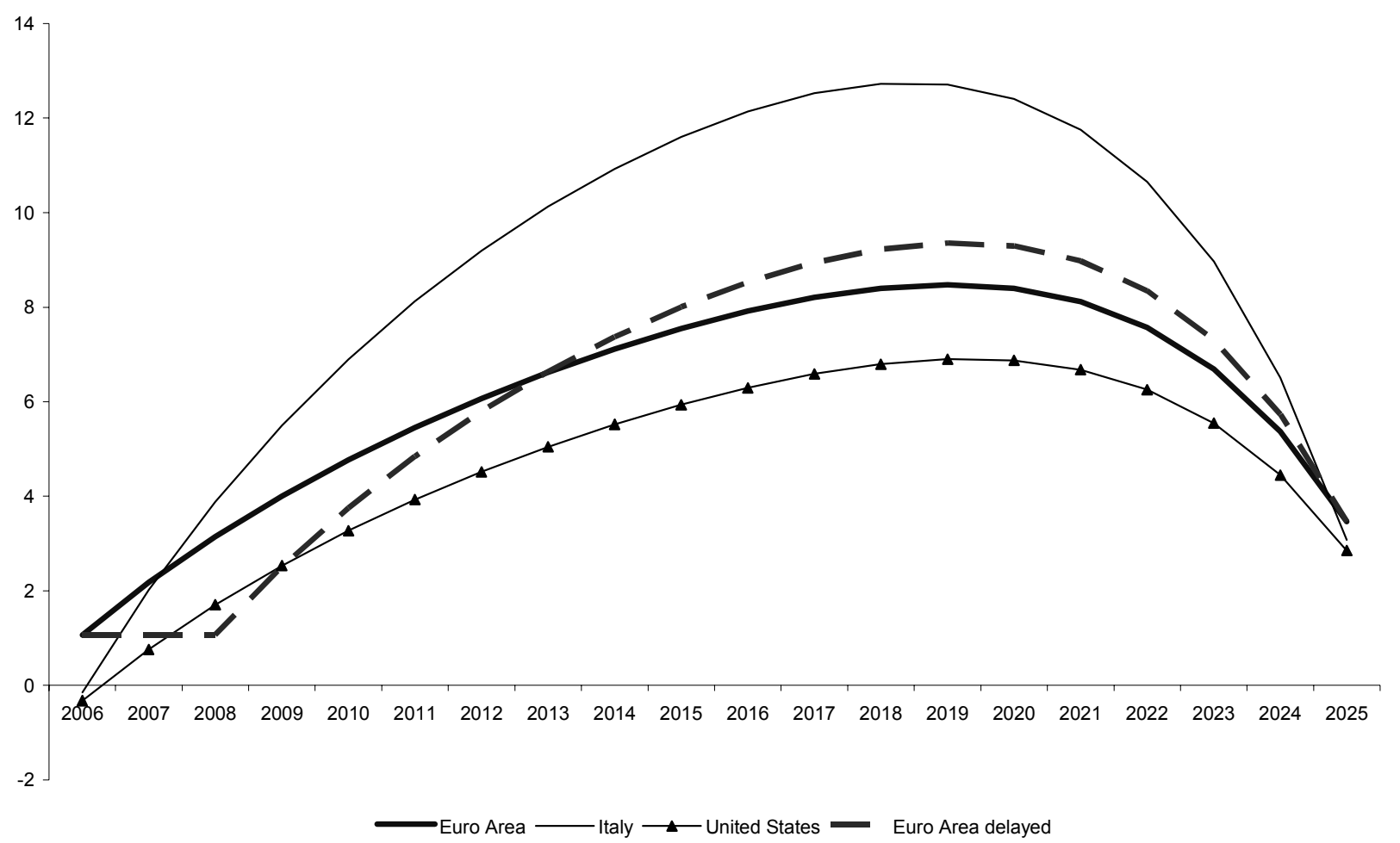

Note: 2006 values and projections are taken from the OECD Economic Outlook 80 database, and subsequent years are model results. The consolidation is achieved over the 2007-25 period, with the exception of the "euro area delayed" case where it takes place between 2009 and 2025.

Source: Author's calculations.

\section{Robustness checks}

\section{No cost attached to maintaining the adjustment}

29. An important robustness check is to assume that political costs arise only from changing fiscal settings and not from maintaining the adjustment. Such a check is important because, while there is general agreement that large changes in fiscal policy settings are costly, there is some doubt as to whether or not a cost is attached to maintaining deviations from today's policy settings. All parameters keep their base case values (in particular $\alpha$ remains equal to 2) with the important exception of $a$ which is set at zero. Table 3 shows that the relative costs of delay become even larger under this set of assumptions than in the base case reported in Table 2. The reason is that the adjustment speed-based component of the loss function is more sensitive to the time available to achieve the consolidation than the size-based component. 
Table 3. Political costs of delay when the loss function is based only on changes in the stance

Relative cost of delay when consolidation starts in 2009 rather than 2007

\begin{tabular}{llllll}
\hline \multicolumn{5}{c}{ Per cent } \\
\hline Euro Area & $39(5 / 13)$ & France & $39(5 / 13)$ & Netherlands & $40(2 / 4)$ \\
Australia & $\mathrm{nb}$ & Germany & $39(5 / 12)$ & New Zealand & $35(0 / 1)$ \\
Austria & $35(2 / 7)$ & Greece & $36(10 / 29)$ & Portugal & $42(7 / 17)$ \\
Belgium & $35(3 / 7)$ & Ireland & $33(1 / 3)$ & Spain & $39(0 / 1)$ \\
Canada & $37(3 / 7)$ & Italy & $39(17 / 44)$ & Sweden & $33(1 / 4)$ \\
Denmark & $42(0 / 0)$ & Japan & $38(41 / 107)$ & United Kingdom & $40(3 / 8)$ \\
Finland & $40(1 / 3)$ & Luxembourg & $31(1 / 5)$ & United States & $39(4 / 11)$ \\
\hline
\end{tabular}

Note: $\mathrm{nb}$ indicates that the debt constraint is not binding, meaning that there is no need to consolidate to reach the target.

Source: Author's calculations.

\section{Different weighting of the loss function}

30. The weights given to the two components of the political cost function (the speed and size of adjustment) are obvious candidates for sensitivity analysis. Table 4 reports results with parameters that are very different from those in the main results: $\alpha=1$ instead of 2 and $a=1$ instead of 0.1 . All other assumptions are as for the main results reported in Table 2. Despite the huge change in the parameters which lie at the core of the model, the results are strikingly similar to the main results reported in Table 2 from a qualitative point of view. This illustrates the robustness of the main conclusion i.e. that waiting is very costly.

Table 4. Political cost of delay with a very different choice of cost parameters

Relative cost of delay when consolidation starts in 2009 rather than 2007

\begin{tabular}{lclclc}
\hline \multicolumn{5}{c}{ Per cent } \\
\hline Euro Area & $6(28 / 457)$ & France & $8(32 / 420)$ & Netherlands & $2(6 / 365)$ \\
Australia & $13(9 / 72)$ & Germany & $8(30 / 366)$ & New Zealand & $1(1 / 215)$ \\
Austria & $3(9 / 296)$ & Greece & $6(60 / 1089)$ & Portugal & $9(57 / 617)$ \\
Belgium & $1(4 / 703)$ & Ireland & $3(7 / 202)$ & Spain & $0(0 / 253)$ \\
Canada & $3(11 / 361)$ & Italy & $12(117 / 982)$ & Sweden & $2(3 / 211)$ \\
Denmark & $0(1 / 227)$ & Japan & $18(312 / 1717)$ & United Kingdom & $15(29 / 188)$ \\
Finland & $1(4 / 300)$ & Luxembourg & $14(20 / 141)$ & United States & $11(30 / 276)$ \\
\hline
\end{tabular}

Source: Author's calculations.

\section{Higher discount rate}

31. The discount rate is a key parameter of the model. A set of results have been computed with a high value for the policy maker's discount rate: $10 \%$. The assumptions are otherwise similar to that underlying the results in Table 2. Table 5 reports the result with this higher discount rate. As expected the costs of inaction are lower, but they remain remarkably large for many countries. 
Table 5. Political cost of inaction with a subjective discount rate of $10 \%$

Relative cost of delay when consolidation starts in 2009 rather than 2007

\begin{tabular}{lclclr}
\hline \multicolumn{5}{c}{ Per cent } \\
\hline Euro Area & $9(4 / 40)$ & France & $11(4 / 38)$ & Netherlands & $3(1 / 28)$ \\
Australia & $16(1 / 7)$ & Germany & $12(4 / 34)$ & New Zealand & $1(0 / 15)$ \\
Austria & $6(1 / 25)$ & Greece & $9(8 / 91)$ & Portugal & $13(7 / 55)$ \\
Belgium & $1(1 / 53)$ & Ireland & $6(1 / 15)$ & Spain & $0(0 / 18)$ \\
Canada & $5(2 / 29)$ & Italy & $16(15 / 99)$ & Sweden & $3(1 / 17)$ \\
Denmark & $1(0 / 16)$ & Japan & $21(40 / 195)$ & United Kingdom & $18(4 / 19)$ \\
Finland & $2(1 / 22)$ & Luxembourg & $16(2 / 13)$ & United States & $15(4 / 26)$ \\
\hline
\end{tabular}

Source: Author's calculations.

\section{More distant horizon}

32. If the consolidation horizon is more distant, the political cost of delay becomes lower but remains sizeable. Table 6 reports estimates of the costs of a four-year delay when the consolidation horizon is 2050 . A four-year delay was chosen to have a comparable ratio of delay to consolidation period as for the main results reported in Table 2. The estimated costs are lower than in the central scenario because a considerable amount of back-loading is occurring (Figure 3). The optimal primary surplus in this scenario rises to $16 \%$ of GDP in Japan in 2043. The reason is simple: a $6 \%$ subjective discount rate implies that incurring a political cost of 100 in 2050 is preferred to a cost of 7 today. The results at such a distant horizon should be taken with caution. The assumption that deviating from today's expenditure, tax and entitlement positions is politically costly may gradually lose some of its validity when looking at very long horizons since underlying political equilibria are likely to evolve over time albeit slowly. Discounting however partly accounts for this effect.

Table 6. Political cost of delay when the consolidation horizon is $\mathbf{2 0 5 0}$

Relative cost of delay when consolidation starts in 2011 rather than 2007

\begin{tabular}{llllll}
\hline \multicolumn{5}{c}{ Per cent } \\
\hline Euro Area & $2(1 / 42)$ & France & $3(1 / 35)$ & Netherlands & $0(0 / 44)$ \\
Australia & $8(2 / 20)$ & Germany & $4(1 / 33)$ & New Zealand & $0(0 / 50)$ \\
Austria & $0(0 / 19)$ & Greece & $1(1 / 111)$ & Portugal & $5(5 / 96)$ \\
Belgium & $1(0 / 66)$ & Ireland & $0(0 / 50)$ & Spain & $0(0 / 49)$ \\
Canada & $0(0 / 33)$ & Italy & $8(5 / 67)$ & Sweden & $0(0 / 16)$ \\
Denmark & $3(1 / 34)$ & Japan & $16(15 / 93)$ & United Kingdom & $9(2 / 23)$ \\
Finland & $0(0 / 41)$ & Luxembourg & $5(3 / 56)$ & United States & $6(1 / 26)$ \\
\hline
\end{tabular}


Figure 3. Consolidation paths at horizon 2050

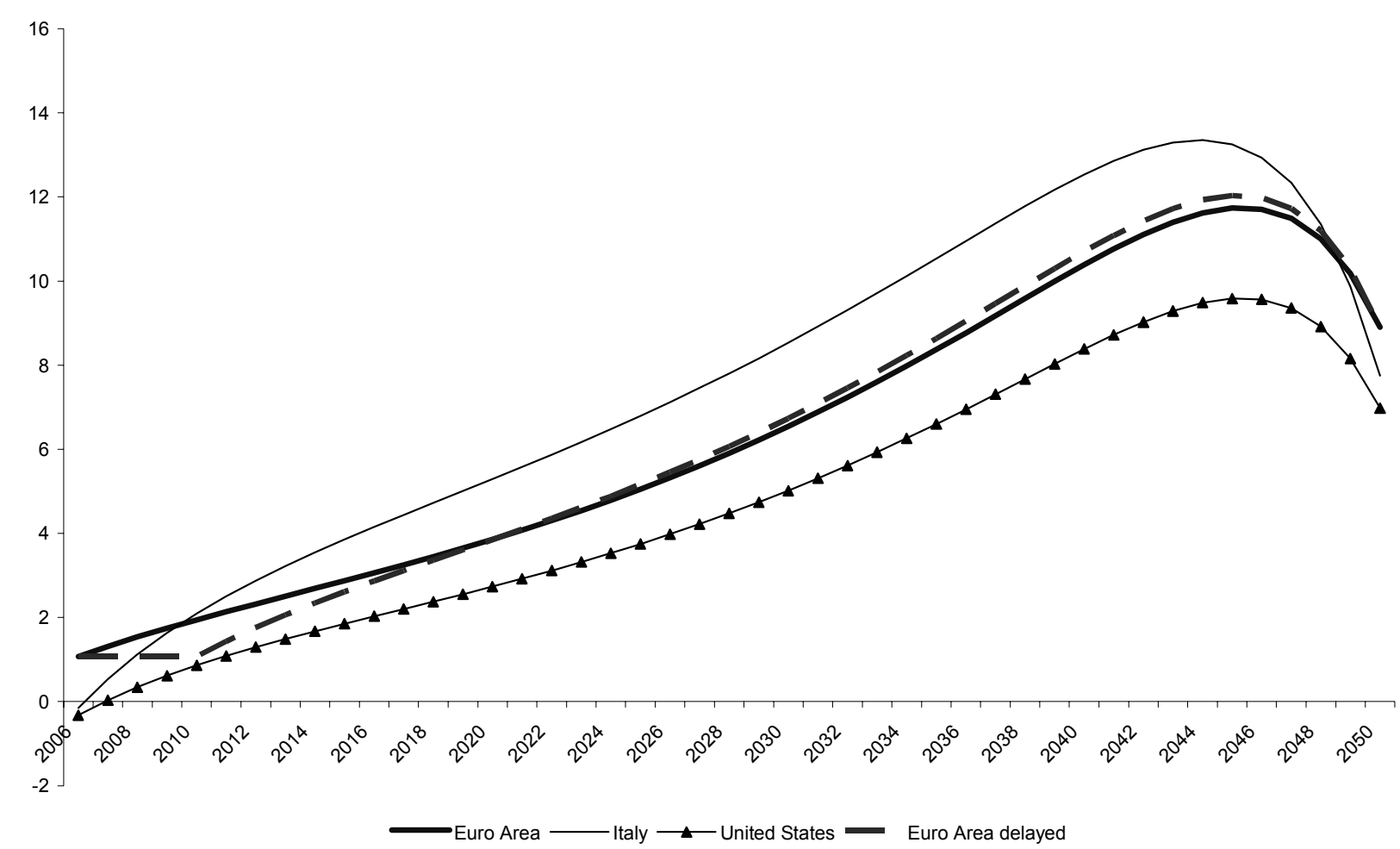

More modest target

33. Another robustness check is to look at consolidation strategies that bring debt to $60 \%$ of GDP by 2025: this is hardly enough to prepare for long-term cost pressures but maybe a more realistic assumption than zero debt. The main results are broadly unchanged in this scenario: postponing consolidation increases costs quite markedly in France, Germany, Greece, Italy, Japan, Portugal, Sweden, the United Kingdom and the United States (Table 7). One feature of this analysis is that there is no need to consolidate to reach the target in a number of countries: Australia, Denmark, Ireland, Luxembourg, New Zealand and Spain. In Austria, Belgium and Canada, delaying consolidation still implies some political costs, but very small ones which round to zero.

Table 7. Political cost of delay when the objective is a $60 \%$ ratio in 2025

Relative cost of delay when consolidation starts in 2009 rather than 2007

\begin{tabular}{lcllll}
\hline \multicolumn{5}{c}{ Per cent } \\
\hline Euro Area & $7(1 / 15)$ & France & $10(1 / 13)$ & Netherlands & $1(0 / 11)$ \\
Australia & $\mathrm{nb}$ & Germany & $10(1 / 11)$ & New Zealand & $\mathrm{nb}$ \\
Austria & $0(0 / 5)$ & Greece & $10(6 / 58)$ & Portugal & $12(4 / 32)$ \\
Belgium & $0(0 / 31)$ & Ireland & $\mathrm{nb}$ & Spain & $\mathrm{nb}$ \\
Canada & $0(0 / 8)$ & Italy & $21(15 / 72)$ & Sweden & $17(0 / 3)$ \\
Denmark & $\mathrm{nb}$ & Japan & $29(53 / 181)$ & United Kingdom & $16(0 / 3)$ \\
Finland & $5(0 / 9)$ & Luxembourg & $\mathrm{nb}$ & United States & $16(1 / 5)$ \\
\hline
\end{tabular}

Note: $\mathrm{nb}$ indicates that the debt constraint is not binding, meaning that there is no need to consolidate to reach the target. Source: Author's calculations. 


\section{Uniform differential between interest and growth rates}

34. To what extent are the results driven by the fiscal outlook or by the differential between interest and growth rates? To answer this question, the model has been run using the same interest rate-growth differential for all countries: $r-\gamma=1 \%$ in Table 8 and $r-\gamma=2 \%$ in Table 9. These results, which are very similar to those obtained under base case assumptions and reported in Table 2, indicate that the fiscal outlook is the main driver behind the finding that delaying consolidation entails large costs in many countries.

Table 8. Political cost of delay with a uniform 1 percentage point interest rate-growth differential

Relative cost of delay when consolidation starts in 2009 rather than 2007

\begin{tabular}{lclllr}
\hline \multicolumn{5}{c}{ Per cent } \\
\hline Euro Area & $13(8 / 59)$ & France & $15(8 / 56)$ & Netherlands & $5(2 / 41)$ \\
Australia & $12(1 / 9)$ & Germany & $15(7 / 46)$ & New Zealand & $1(0 / 21)$ \\
Austria & $9(4 / 38)$ & Greece & $16(28 / 182)$ & Portugal & $16(12 / 78)$ \\
Belgium & $4(3 / 77)$ & Ireland & $13(4 / 29)$ & Spain & $3(1 / 30)$ \\
Canada & $9(4 / 46)$ & Italy & $18(24 / 129)$ & Sweden & $6(2 / 26)$ \\
Denmark & $0(0 / 22)$ & Japan & $25(74 / 294)$ & United Kingdom & $23(7 / 30)$ \\
Finland & $6(2 / 36)$ & Luxembourg & $20(4 / 20)$ & United States & $19(8 / 43)$ \\
\hline
\end{tabular}

Source: Author's calculations.

Table 9. Political cost of delay with a uniform 2 percentage point interest rate-growth differential

Relative cost of delay when consolidation starts in 2009 rather than 2007

\begin{tabular}{lrlllr}
\hline \multicolumn{5}{c}{ Per cent } \\
\hline Euro Area & $15(10 / 69)$ & France & $17(11 / 65)$ & Netherlands & $7(3 / 46)$ \\
Australia & $11(1 / 9)$ & Germany & $17(9 / 54)$ & New Zealand & $2(0 / 22)$ \\
Austria & $12(5 / 45)$ & Greece & $18(37 / 209)$ & Portugal & $18(16 / 88)$ \\
Belgium & $5(5 / 89)$ & Ireland & $15(5 / 32)$ & Spain & $4(1 / 34)$ \\
Canada & $11(6 / 53)$ & Italy & $20(31 / 153)$ & Sweden & $8(3 / 31)$ \\
Denmark & $0(0 / 24)$ & Japan & $27(93 / 348)$ & United Kingdom & $25(9 / 34)$ \\
Finland & $8(3 / 39)$ & Luxembourg & $22(4 / 20)$ & United States & $22(11 / 50)$ \\
\hline
\end{tabular}

Source: Author's calculations.

\section{Numerical solution}

35. Finally, the validity of the analytical solution derived for the model has been checked by using numerical methods to solve the optimisation problem. Allowing for the discrepancy between continuous and discrete time, the results are identical. The analytical solution presented above has been preferred to numerical methods primarily because its functional form makes economic mechanisms apparent. In particular, the factors $e^{\frac{1}{2} \delta t}$ and $e^{\delta t}$ in front of the three terms of equation (16) manifest that a higher subjective discount rate translates into a more back-loaded consolidation strategy. 


\section{A variant with an infinite time horizon}

36. What is the politically optimal consolidation strategy if the policy maker is offered an infinite time horizon rather than being faced with a fixed date by which sustainability must be restored? A variant of the model indicates that the optimal strategy is to put off adjustment indefinitely unless the policy maker discounts the future with a very low rate. If the policy maker indeed has a sufficiently low discount rate, the cost of delaying consolidation rises very fast over time.

\section{Specification}

37. Starting from the initial level $d^{0}$ of the primary deficit, the problem is to find the adjustment path $\left(d_{t}\right)_{t=0}^{+\infty}$ that minimises the loss function (28). As in the main case, the debt ratio evolves in accordance with the debt accumulation equation (6). A weak boundary condition is that the debt ratio remains bounded (Equation 29). An apparently stronger (but in fact equivalent as will be shown below) boundary condition is to assume that the debt ratio converges to zero (Equation 30 ).

$$
\begin{aligned}
& L=\int_{0}^{+\infty}\left(\alpha \dot{d}_{t}^{2}+a d_{t}^{2}\right) e^{-\delta t} d t \\
& \text { (29) } \sup _{t \in[0 ;+\infty}\left|b_{t}\right|<+\infty \\
& \text { (30) } \quad \lim _{t \rightarrow+\infty} b_{t}=0
\end{aligned}
$$

\section{Solution}

38. The general solution is derived exactly as for the finite time problem laid out above. The functional form of the politically optimal paths are given by (20) for the adjustment effort and (24) for the debt ratio. Developing the right-hand side in (24) yields Equation 31 which is a more convenient formulation for the task at hand. When time $t$ goes to infinity, the implicit debt associated from long-term cost pressures arising over the period $[0, t]$, expressed as a ratio $\hat{b}_{0}^{t}$ to GDP, converges to a finite value $\hat{b}_{0}^{\infty}$ given by Equation 32 . This value $\hat{b}_{0}^{\infty}$ - which is equal to the implicit debt ratio associated with long-term cost pressures over the entire future - is necessarily finite because long-term cost pressures $\left(x_{t}\right)$ cannot exceed $100 \%$ of GDP and are therefore bounded, which in turn implies that the integral (32) converges.

$$
d_{t}=c_{1} e^{\rho_{1} t}+c_{2} e^{\rho_{2} t}+k e^{(\delta-r+\gamma) t}
$$

$$
\begin{aligned}
b_{t}=\left[b_{0}+\hat{b}_{0}^{t}-\right. & \left.\frac{c_{1}}{\rho_{1}-r+\gamma}-\frac{c_{2}}{\rho_{2}-r+\gamma}-\frac{k}{\delta-2(r-\gamma)}\right] e^{(r-\gamma) t}+ \\
& \frac{c_{1}}{\rho_{1}-r+\gamma} e^{\rho_{1} t}+\frac{c_{2}}{\rho_{2}-r+\gamma} e^{\rho_{2} t}+\frac{k}{\delta-2(r-\gamma)} e^{(\delta-(r-\gamma)) t}
\end{aligned}
$$

$$
\hat{b}_{0}^{\infty}=\int_{0}^{+\infty} x_{t} e^{-(r-\gamma) t} d t<+\infty
$$


39. Equation 31 shows that the weak boundary condition of a bounded debt ratio is in practice equivalent to the a priori stronger requirement of converging to zero. Because it contains only exponential terms, and barring zero probability events where one of the exponents is equal to zero, the optimal path for the debt ratio either converges to zero or diverges to plus or minus infinity.

40. Before solving the problem, it is useful to note that $\rho_{1}>0$ and $\rho_{2}<0$. Both inequalities stem directly from the definition of $\rho_{1}$ and $\rho_{2}$ in Equation 19. As a consequence, the convergence of the debt ratio requires that $c_{1}$ be equal to zero (33).

$$
c_{1}=0
$$

\section{Optimal path when the discount rate is higher than the interest rate-growth differential}

41. The interest rate-growth differential is usually small and well below the $6 \%$ parameter value that is assumed for the policy maker's discount rate in the main case (Inequality 34). $\delta-r+\gamma$ is therefore positive, implying that $e^{(\delta-r+\gamma) t}$ diverges. Nonetheless, the adjustment effort $d_{t}$ has to remain bounded since the primary surplus cannot be larger than GDP. A consequence is that the variable $k$ must be equal to zero, which in turns means that (20) collapses into $d_{t}=c_{2} e^{\rho_{2} t}$. At time $t=0$ the corrected adjustment effort is by definition equal to the primary deficit $d^{0}$, which means that $c_{2}=d^{0}$. The politically optimal paths for adjustment and debt are hence given by 35 and 36 .

$$
\begin{gathered}
\text { (34) } \quad r-\gamma<\delta \\
\text { (35) } \quad d_{t}=d^{0} e^{\rho_{2} t} \\
b_{t}=\left[b_{0}+\hat{b}_{0}^{t}-\frac{d^{0}}{\rho_{2}-r+\gamma}\right] e^{(r-\gamma) t}+\frac{d^{0}}{\rho_{2}-r+\gamma} e^{\rho_{2} t}
\end{gathered}
$$

Features of the optimal path when the interest rate-growth differential is positive

42. In usual times, governments borrow at real long-term interest rates that are higher than their potential growth rate $(r-\gamma>0)$. When the interest rate-growth differential is positive, the first term in Equation 36 is in general explosive and the debt ratio diverges. ${ }^{11}$ The only exception is if the government is initially running a strong surplus $\left(-d^{0}\right)$ that verifies $(37)$, in which case the debt ratio converges to zero at infinity. Interestingly, Equation 37 describes a situation where the government is initially generating a primary surplus a bit larger than the level that avoids any build-up in the sum of market and implicit liabilities. ${ }^{12}$ In other words, if the government is already following a politically optimal consolidation strategy, it pays to keep doing so. In all other cases, the politically optimal strategy is to let the debt ratio diverge.

$$
-d^{0}=\left(-\rho_{2}+r-\gamma\right)\left(b_{0}+\hat{b}_{0}^{\infty}\right)
$$

11. If the government is initially generating a surplus $-d^{0}$ greater than $\left(-\rho_{2}+r-\gamma\right)\left(b_{0}+\hat{b}_{0}^{\infty}\right)$, then the debt ratio will diverge to minus infinity, meaning an explosive accumulation of net assets.

12. Equation 19 indicates that $\rho_{2}$ is small and negative. 
43. In other words, the politically optimal path is to let the debt ratio grow exponentially over time when the situation meets the four following criteria:

1. there is no fixed time horizon by which sustainability must be restored;

2. the discount rate is larger than the interest rate-growth differential;

3. the interest rate-growth differential is positive; and

4. the government is not already following an optimal consolidation strategy (i.e. it does not run a primary balance slightly above the level that avoids any build-up in the sum of market and implicit liabilities).

44. This finding should not be taken too literally. It assumes a fixed interest rate in spite of a situation where the debt ratio shoots up exponentially to infinity. In practice the interest rate would go up and even accelerate (Koutsogeorgopoulou et al., 2007) while growth would suffer. Ultimately the interest rategrowth differential would become larger than the discount rate, in which case it becomes politically optimal to consolidate (see below). Nonetheless, the main conclusion that can be drawn is that debt targets with fixed deadlines are useful tools to encourage consolidation.

Features of the optimal path when the interest rate-growth differential is negative

45. In the unlikely event that the long-term interest rate on government bonds is lower than the economy's potential growth rate $(r-\gamma<0)$, the situation becomes very different. The debt dynamics, which is driven by the interest rate-growth differential, becomes contractionary rather than explosive. The politically optimal strategy (given by Equation 35) is to bring the corrected adjustment effort gently to zero. The corresponding debt trajectory (Equation 36 ) shows that the debt ratio $b_{t}$ converges to zero since any initial imbalance dissipates under the impact of the contractionary debt dynamics.

\section{Optimal path when the discount rate is lower than the interest rate-growth differential}

46. There are times when policy makers will operate with a discount rate lower than the interest rategrowth differential. One reason can be that they exhibit a particularly acute degree of benevolence towards future generations. Another reason can be that the build-up of debt in the past has been such that the real interest rate on government bonds has shot up well above the long-term growth rate of the economy (which may have simultaneously suffered from unsound fiscal policies). Whatever the actual reason is, this section deals with situations that verify (38).

$$
0<\delta<r-\gamma
$$

47. In this case, convergence of the debt ratio along its politically optimal trajectory only requires zero coefficients in front of $e^{(r-\gamma) t}$ and $e^{\rho_{1} t}$, two conditions summarised in Equations 39 and $33 .{ }^{13}$ In addition, the primary deficit before consolidation has to be equal to the last observed historic value hence the additional equation 40 has to hold too. The problem therefore boils down to solving the three-variable three-equation system (41).

13. The difference with the situation where $\delta$ is greater than $r-\gamma$ is that now $e^{(\delta-(r-\gamma)) t}$ converges to zero, which implies that $k$ no longer need be equal to zero for the quantity $k e^{(\delta-(r-\gamma)) t}$ to converge. 


$$
\begin{gathered}
b_{0}+\hat{b}_{0}^{\infty}-\frac{c_{1}}{\rho_{1}-r+\gamma}-\frac{c_{2}}{\rho_{2}-r+\gamma}-\frac{k}{\delta-2(r-\gamma)}=0 \\
\text { (33) } \quad c_{1}=0 \\
\text { (40) } \quad c_{1}+c_{2}+k=d^{0}
\end{gathered}
$$

$$
\left(\begin{array}{ccc}
1 & 1 & 1 \\
\frac{1}{\rho_{1}-r+\gamma} & \frac{1}{\rho_{2}-r+\gamma} & \frac{1}{\delta-2(r-\gamma)} \\
1 & 0 & 0
\end{array}\right)\left(\begin{array}{c}
c_{1} \\
c_{2} \\
k
\end{array}\right)=\left(\begin{array}{c}
d^{0} \\
b_{0}+\hat{b}_{0}^{\infty} \\
0
\end{array}\right)
$$

48. Simulation results in Table 10 show that in this situation the cost of delaying consolidation rises very quickly despite the absence of a fixed horizon. Simulations have been run using a discount rate of $2 \%$ and an interest rate-growth differential of 3 percentage points for all countries. Other parameter values are as in the main case.

Table 10. Political cost of delay with an infinite time horizon and a low discount rate

Relative cost of delay when consolidation starts in 2009 rather than 2007

\begin{tabular}{lllrlc}
\hline \multicolumn{5}{c}{ Per cent } \\
\hline Euro Area & $7(17 / 253)$ & France & $7(14 / 201)$ & Netherlands & $5(12 / 248)$ \\
Australia & $1(1 / 102)$ & Germany & $7(13 / 182)$ & New Zealand & $5(13 / 277)$ \\
Austria & $5(5 / 110)$ & Greece & $8(67 / 872)$ & Portugal & $8(45 / 566)$ \\
Belgium & $3(11 / 349)$ & Ireland & $8(30 / 383)$ & Spain & $5(16 / 339)$ \\
Canada & $5(11 / 200)$ & Italy & $8(27 / 317)$ & Sweden & $4(4 / 93)$ \\
Denmark & $2(3 / 165)$ & Japan & $12(60 / 488)$ & United Kingdom & $10(15 / 147)$ \\
Finland & $5(12 / 241)$ & Luxembourg & $10(34 / 348)$ & United States & $9(15 / 167)$ \\
\hline
\end{tabular}

Source: Author's calculations.

\section{Lessons, caveats and scope for further research}

49. In sum, the potential political cost of consolidating public finances increases very quickly as action is postponed. In the main scenario for the euro area, it rises by $14 \%$ if consolidation is put off for two years. This conclusion is very robust to changes in the design of scenarios, in the specification of the loss function and in parameter values including the policy maker's subjective discount rate. A variant of the model also shows the importance of setting a deadline for consolidation, however distant it may be. If there is no deadline but instead an infinite time horizon, the politically optimal strategy for a myopic policy maker is to postpone adjustment indefinitely, a strategy which results in an exploding debt ratio.

50. In addition to the factors captured by the model, some other drivers are likely to add to the cost of inaction. Negative feedbacks from tax hikes on real GDP growth can raise the cost of consolidation (Cournède and Gonand, 2006). Because such feedbacks are likely to be non-linear, they will magnify the cost of delays more than proportionately. Similarly, a higher public debt ratio is likely to have a non-linear effect on the real interest rate and hence will increase the cost of inaction (Bernoth et al., 2006). 
51. One caveat concerning the model presented above is that it deals symmetrically with positive and negative changes in the fiscal stance even though tightening may be politically more costly than loosening. An extension of the analysis would be to use a kinked loss function that assigns different values to negative and positive changes. This extension, however, would probably come at the cost of not having an analytical solution for the problem but only numerical results.

\section{REFERENCES}

Alesina, A. and A. Drazen (1991), "Why Are Stabilisations Delayed?", The American Economic Review, Vol. 81, No. 5.

Alesina, A., R. Perotti and J. Tavares (1998), “The Political Economy of Fiscal Adjustments”, Brookings Papers on Economic Activity, Vol. 1.

Bernoth, K., J. von Hagen and L. Schuknecht (2006), "Sovereign Risk Premiums in the European Government Bond Market", GESY Discussion Paper, No. 151, University of Mannheim.

Bourguignon, J.P. (1989), Calcul Variationnel, Editions de l'Ecole Polytechnique, Palaiseau.

Bradley, J., K. Whelan, and J. Wright (1993), Stabilisation and Growth in the EC Periphery, Aldershot, Avebury.

Brender, A. and A. Drazen (2006), "Political Implications of Fiscal Performance in OECD Countries", in Franco, D., Ed. (2006), Proceedings of the 8th International Public Finance Workshop, Banca d'Italia, forthcoming.

Buti, M. and P. Van den Noord (2004), "Fiscal Discretion and Elections in the Early Years of EMU", Journal of Common Market Studies, Vol. 42.

Cotis, J.-P. and V. Koen (2006), "The Political Economy of Strong Fiscal Adjustments in Aspiring Euro Area Countries", in Fiscal Policy and the Road to the Euro, National Bank of Poland, Warsaw.

Cournède, B. and F. Gonand (2006), "Restoring Fiscal Sustainability in the Euro Area: Raise Taxes or Curb Spending?", OECD Economics Department Working Papers, No. 520, OECD, Paris.

Dang, T.-T., P. Antolin and H. Oxley (2001), "Fiscal Implications of Ageing: Projections of Age-Related Spending", OECD Economics Department Working Papers, No. 305, OECD, Paris.

Dornbusch, R. (1991), "Credibility and Stabilisation”, The Quarterly Journal of Economics, Vol. 106, No. 3.

European Commission (2006), "Public Finances in EMU 2006”, European Economy, Vol. 2006, No. 3, Brussels. 
EU Economic Policy Committee (2006), Impact of Ageing Populations on Public Spending, European Commission, Brussels.

Gallon, S. and E. Masse (2004), "Arbitrage intertemporel, risque et actualisation", Document de travail du Ministère de l'environnement, Paris.

Giavazzi, F. and M. Pagano (1996), "Non-Keynesian Effects of Fiscal Policy Changes: International Evidence and the Swedish Experience", Swedish Economic Policy Review, Vol. 3.

Gourinchas, P.-O. and J. Parker (2002), “Consumption over the Life-Cycle”, Econometrica, 70(1).

Greek Ministry of Finance (2005), The 2005 Update of the Hellenic Stability and Growth Program 20052008, Athens.

Hughes-Hallett, A. and P. McAdam (1998), "Fiscal Deficit Reductions in Line With the Maastricht Criteria for Monetary Union: An Empirical Analysis" in J. Frieden, D. Gros and E. Jones (eds.), The New Political Economy of EMU, Rowman and Littlefield, Denver.

Koutsogeorgopoulou, V. and D. Turner (2007), "The Costs of Delaying Fiscal Consolidation; How Rapidly should Greece react to Future Fiscal Pressures from Ageing?", OECD Economics Department Working Papers, OECD, Paris, forthcoming.

Lavigne, R. (2006), "The Institutional and Political Determinants of Fiscal Adjustment", Bank of Canada Working Paper, No. 2006-1, Ottawa.

OECD (2005), OECD Economic Surveys: Denmark, Paris.

OECD (2006), "Projecting OECD Health and Long-term Care Expenditures: What Are the Main Drivers?", OECD Economics Department Working Papers, No. 477, Paris.

Visco, I. (Ed.) (2005), “Ageing and Pension System Reform: Implications for Financial Markets and Economic Policies”, in Financial Market Trends, November 2005 Supplement, OECD, Paris.

Von Hagen, J., A. Hughes-Hallet and R. Strauch (2001), "Budgetary Consolidation in EMU", Economic Papers, No. 148, European Commission, Brussels. 


\section{WORKING PAPERS}

The full series of Economics Department Working Papers can be consulted at www.oecd.org/eco/Working_Papers/

547. The impact on growth of higher efficiency of public spending on schools (March 2007) Frédéric Gonand

546. Performance indicators for public spending efficiency in primary and secondary education (February 2007) Douglas Sutherland, Robert Price, Isabelle Joumard and Chantal Nicq.

545. Monetary policy and macroeconomic stability in Latin America: the cases of Brazil, Chile, Colombia and Mexico

(February 2007) Luiz de Mello and Diego Moccero

544. The Brazilian "tax war": the case of value-added tax competition among the states (February 2007) Luiz de Mello

543. Public spending efficiency: institutional indicators in primary and secondary education (January 2007) Frédéric Gonand, Isabelle Joumard and Robert Price

542. Enhancing turkey's growth prospects by improving formal sector business conditions (January 2007) Rauf Gönenç, Willi Leibfritz, Gökhan Yilmaz

541. Fiscal relations across levels of government in Australia (January 2007) Vassiliki Koutsogeorgopoulou

540. Russian manufacturing and the threat of 'Dutch Disease': A comparision of competitiveness developments in Russia and Ukrainian industry

(January 2007) Rudiger Ahrend, Donato de Rosa and William Tompson

539. Stimulating innovation in Russia: The role of institutions and policies (January 2007) Christian Gianella and William Tompson

538. Healthcare reform in Russia: problems and prospects (January 2007) William Tompson

537. A golden rule for Russia? How a rule-based fiscal policy can allow a smooth adjustment to the new terms of trade

(January 2007) Christian Gianella

536. From "clientelism" to a "client-centred orientation"? The challenge of public administration reform in Russia (January 2007) William Tompson

535. Has the rise in debt made households more vulnerable?

(December 2006) Nathalie Girouard, Mike Kennedy and Christophe André

534. Social security reform in Brazil: Achievements and remaining challenges (December 2006) Fabio Giambiagi and Luiz de Mello

533. Improving labour utilisation in Brazil (December 2006) Luiz de Mello, Naércio Menezes Filho and Luiz G. Scorzafave

532. Boosting innovation performance in Brazil

(December 2006) Carlos H. de Brito Cruz and Luiz de Mello

531. Consolidating macroeconomic adjustment in Brazil 
(December 2006) Luiz de Mello and Diego Moccero

530. Product market regulation in the non-manufacturing sectors of OECD countries: Measurement and highlights (December 2006) Paul Conway and Giuseppe Nicoletti

529. The Turkish pension system: further reforms to help solve the informality problem (November 2006) Anne-Marie Brook and Edward Whitehouse

528. Policies to improve Turkey's resilience to financial market shocks (November 2006) Anne-Marie Brook.

527. Upgrading Japan's innovation system to sustain economic growth (November 2006 Randall S. Jones and Tadashi Yokoyama

526. Strengthening the integration of Japan in the world economy to benefit more fully from globalisation (November 2006) Randall S. Jones and Taesik Yoon

525. OECD's FDI regulatory restrictiveness index: Revision and extension to more economies (November 2006) Sven Blöndal and Alain de Serres

524. Globalisation and inflation in the OECD economies (November 2006) Nigel Pain, Isabell Koske and Marte Sollie

523. Identifying determinants of Germany's international price competitiveness - A structural VAR approach (November 2006) Martin Meurers

522. Short-term pain for long-term gain: the impact of structural reform on fiscal outcomes in EMU (November 2006) Paul van den Noord and Boris Cournède

521. Interactions between monetary and fiscal policy: How monetary conditions affect fiscal consolidation (November 2006) Rudiger Ahrend, Pietro Catte and Robert Price

520. Restoring fiscal sustainability in the Euro Area: raise taxes or curb spending? (October 2006) Boris Cournède and Frédéric Gonand

519. Should Measures of Fiscal Stance be Adjusted for Terms of Trade Effects (October 2006) David Turner

518. Monetary policy and inflation expectations in Latin America: Long-run effects and volatility spillovers (October 2006) Luiz de Mello and Diego Moccero

517. Social safety nets and structural adjustment (September 2006) Paul van den Noord, Nathalie Girouard and Christophe André

516. Adapting the Icelandic education system to a changing environment (September 2006) Hannes Suppanz

515. Forecasting monthly GDP for Canada (September 2006) Annabelle Mourougane

514. Finland's housing market: reducing risks and improving policies (September 2006) Laura Vartia

513. The Danish housing market: Less subsidy and more flexibility (September 2006) Espen Erlandsen, Jens Lundsgaard and Felix Huefner 